\title{
On Mathematical Equalities and Inequalities in the Life Table: Something Old and Something New
}

\author{
David A. Swanson ${ }^{1} \cdot$ Lucky M. Tedrow $^{2}$ \\ Received: 15 December 2017 / Accepted: 30 May 2018 / Published online: 26 June 2021 \\ (C) The Author(s) 2021
}

\begin{abstract}
This paper discusses known mathematical equalities and inequalities found within life tables and proceeds to identify two new inequalities. The first (theorem 1) is that at any given age $\mathrm{x}$, the sum of mean years lived and mean years remaining exceeds life expectancy at birth when age is greater than zero and less than the maximum lifespan. The second inequality (theorem 2) applies to the entire population and shows that the sum of mean years lived and mean years remaining exceeds life expectancy at birth. Illustrations of the two inequalities are provided as well as a discussion.
\end{abstract}

\section{Résumé}

Cet article examine les égalités et les inégalités mathématiques connues dans les tables de mortalité et procède à l'identification de deux nouvelles inégalités. La premiére (théorème 1) est que,à tout âge $\mathrm{x}$ donné, la somme d'années moyennes vécues et d'années moyennes restantes dépasse l'espérance de vie à la naissance lorsque l'âge est supérieur à zéro et inférieur à la durée de vie maximale. La deuxième inégalité (théorème 2) s'applique à l'ensemble de la population et montre que la somme d'années moyennes vécues et d'années moyennes restantes dépasse l'espérance de vie à la naissance. Des illustrations des deux inégalités sont fournies ainsi qu'une discussion.

Keywords Carey's Equality Theorem $\cdot$ Life years lost $\cdot$ Life expectancy at birth $\cdot$ Mean years lived $\cdot$ mean years remaining $\cdot$ variance in age at death

Mots-clé théoréme d'égalité de Carey · années de vie perdues · espérance de vie à la naissance · nombre d'années vécues · nombre d'années restantes · variance de l'âge au décès

David A. Swanson

dswanson@ucr.edu

Lucky M. Tedrow

Lucky.tedrow@wwu.edu

Extended author information available on the last page of the article 


\section{Introduction}

Life tables represent an important component of demography. Not only do they serve as methodological and conceptual tools (Burch, 2018; Swanson \& Tedrow, 2012 and Yusuf et al., 2014), but they support a wide range of both applied work (Kintner \& Swanson, 1994; Richards \& Donaldson, 2010; Siegel, 2002; Smith et al., 2013; Thomas \& Bao, 2016) and academic work (Shkolnikov et al., 2003; Swanson \& Sanford, 2012; Trovato \& Lalu, 2001; Yashin et al., 2016). As such, it should not be surprising that life tables have been widely studied and that many of their defining characteristics, such as their internal mathematical equalities, have been described (Kintner, 2004). In addition to the obvious equalities such as the crude birth rate being equal to the crude death rate, research has revealed that (1) mean years lived is equal to mean years remaining, which is known as Carey's Equality Theorem (Vaupel, 2009) and (2) the distribution of age composition is equal to the distribution of remaining lifetimes (Carey et al., 2008; Rao \& Carey, 2014; Vaupel, 2009). To these equalities, the following can be added: (1) mean age is equal to mean years lived (Rao \& Carey, 2014) and (2) mean age is equal to mean years remaining (Kim \& Aron, 1989).

Inequalities among life table functions have not attracted as much interest as equalities, but they have been examined. Pearson (1924), for example, showed that the life expectancy at any given age $\mathrm{x}$ was greater than the mean age of all persons living who had lived at least to age $\mathrm{x}$. Canudas-Romo (2010) explored differences found among the mean age at death (life expectancy at birth), median age at death, and modal age at death as a means of characterizing longevity in a population. These same measures also are found in a study of longevity in England and Wales by the Office of National Statistics (2017) that finds in life tables where deaths become concentrated in older ages, the modal age at death is higher than the median, and the median age at death is higher than that of the mean age at death (life expectancy at birth).

To these observations on life table inequalities, we add two more by demonstrating: (1) that at any given age $\mathrm{x}$, the sum of mean years lived and mean years remaining exceeds life expectancy at birth in a given stationary population, where $0<x<\omega$ (maximum lifespan); and (2) that for a stationary population as a whole, the sum of mean years lived and mean years remaining exceeds life expectancy at birth. We discuss this set of inequalities and provide an empirical illustration of them. Before we turn to the examination of these inequalities, however, it is useful to briefly cover relevant life table equalities examined by other researchers.

\section{Something Old: Known Relevant Equalities}

Kim and Aron (1989) provide a proof that mean age in a stationary population, $\mu \mathrm{a}$, is equal to mean expected years remaining, $\mu \mathrm{r}$ :

$$
\mu a=\mu r
$$

Vaupel (2009) demonstrated that that the mean number of years lived in a stationary population, $\mu \mathrm{l}$, is equal to the mean expected years remaining, $\mu \mathrm{r}$ : 


$$
\mu r=\mu l
$$

Another equality of interest was identified by Pressat (1972: 479-480), who examined the relationship between mean age of a stationary population and life expectancy at birth and found (in the notation we use):

$$
\mu a=0.5\left(e_{0}+\left(\sigma^{2} / e_{0}\right)\right)
$$

where:

$\mu \mathrm{a}$, is defined as before (mean age of the stationary population);

$e_{0}($ life expectancy at birth $)=\mu($ mean lifetime $)=u d($ mean age at death);

$\sigma^{2}=$ variance in age at death.

Pressat's identification of Eq. (3) was independently re-discovered by Morales (1989) and identified as a re-discovery by Preston (1991). Ryder (1975: 8-11) also used Eq. (3) and noted that $\sigma 2 / e_{0}$ can be interpreted as the coefficient of variation in regard to age at death in a stationary population. ${ }^{1}$

\section{Something Not Quite New: Two Known Relevant Equalities Combined}

Because of the proof provided by Kim and Aron (1989) stated as an Eq. (1), $\mu \mathrm{a}=\mu \mathrm{r}$, and the proof provided by Vaupel (2009) stated as Eq. (2), $\mu a=\mu$ l, we can easily see an equality not hitherto explicitly stated, namely, that the mean age of a stationary population is equal to its mean years remaining and, therefore, equal to its mean years lived:

$$
\mu a=\mu l=\mu r
$$

We use the equalities found in Eqs. (3) and (4) in proving the second of the two inequality theorems presented in this paper, namely, that the sum of mean years lived and mean years remaining exceeds mean lifetime. ${ }^{2}$ Before turning to it, however, we first prove theorem 1: The sum of mean years lived to age $\mathrm{x}$ and mean years remaining at age $\mathrm{x}$ is greater than mean lifetime.

\section{Something New: Two Inequalities}

Each of the two new inequality theorems we identify can be examined from either the traditional life table perspective, where age is treated as discrete or from the perspective where age is treated as continuous. Noting that the proofs of these two theorems from a discrete perspective are in the appendix, we take the continuous perspective here. ${ }^{3}$

\section{Theorem 1}

When $0<\mathrm{x}<\omega$, then $\mu \mathrm{l}_{\mathrm{x}}+\mu \mathrm{r}_{\mathrm{x}}>\mu$.

Where: $x=$ age

$\omega=$ maximum age

$\mu l_{x}=$ mean years lived to age $\mathrm{x}$ 
$\mu r_{x}=$ mean years remaining at age $\mathrm{x}$

$\mu=$ mean lifetime

\section{Proof:}

Following the general argument laid out by Kim and Aron (1989), we assume that lifetime is characterized by a non-negative random variable $X$, with $S(x)$ as the corresponding survival function, and where $S(0)=1$ (which is equivalent to setting the radix, $k=l_{0}$, $=1$, see, e.g., Swanson $\&$ Tedrow, 2012), so that:

$$
\begin{aligned}
& \mu l x=\int_{0}^{x} S(y) d y \\
& \mu r x=\int_{x}^{\omega} S(y) d y / S(x) . \\
& \mu=\int_{0}^{\omega} S(x) d x
\end{aligned}
$$

The sum, $\mu \mathrm{l}_{\mathrm{x}}+\mu \mathrm{r}_{\mathrm{x}}$, can be written as $\mu l_{x}+\mu r_{x}=\int_{0}^{x} S(y) d y+\int_{x}^{\omega} S(y) d y / S(x)$. When $\mathrm{x}=$ 0 , then $\int_{0}^{x} S(y) d y+\int_{x}^{\omega} S(y) d y / S(x)$ reduces to $\int_{0}^{\omega} S(y) d y$ and is equivalent to $\int_{0}^{\omega} S(x) d x$, which is equal to $\mu$. And because $S(x)<1$, when $0<X<\omega$, then $\mu \mathrm{l}_{x}+\mu \mathrm{r}_{x}>\mu$, which completes the proof of theorem 1.

\section{Theorem 2}

The second of the two new inequalities we identify is related to the first inequality, but distinct in that it refers to the stationary population in general rather than to specific ages:

$$
\mu l+\mu r>\mu
$$

Where $\mu \mathrm{l}, \mu \mathrm{r}$, and $\mu$ are defined as before.

\section{Proof}

Recall from Eq. (3) that $\mu \mathrm{a}=0.5\left(\mu+\left(\sigma^{2} / \mu\right)\right)$. With $S(x)$ as the survival function and $S(0)=1$, then the age density function of a stationary population, $c(x)$, is given by $S(x) / \mu$ (see, e.g., Frauenthal, 1986) with a mean age, $\mu a$. Recalling from Eq. (4) that $\mu a=\mu \mathrm{l}=\mu \mathrm{r}$, then $2 \mu a=2 \mu l=2 \mu r$. Because $2 \mu a=\mu l+\mu r=\mu+\left(\sigma^{2} / \mu\right)$, then it follows that $\mu l+\mu r>\mu$, where $\sigma^{2}>0$; and where $\sigma^{2}=0$, then $\mu l+\mu \mathrm{r}_{\mathrm{r}}=\mu$. This completes the proof.

\subsection{Illustration of Theorem 1}

Using a 1990 complete US life table (both sexes combined, by single years of age to age 110) from the Human Mortality Database (2009) as an illustration of a stationary population, we examine $\mu \mathrm{l}_{\mathrm{x}}+\mu \mathrm{r}_{\mathrm{x}}$. Because the terminal age is 110 in this life table, we set maximum life slightly above it, at $\omega=111$, for purposes of illustration. Our examination is summarized by Fig. 1, which provides a plot of the relationship between age ( $\mathrm{x}$ axis) and $\mu l_{x}+\mu r_{x}$. (y axis). Life expectancy at birth for this population is 75.4 years. When age $(\mathrm{x})=0, \mu \mathrm{l}_{x}+\mu \mathrm{r}_{x} .=e_{0}$; and when age $(\mathrm{x})=111, \mu \mathrm{l}_{\mathrm{x}}+\mu \mathrm{r}_{\mathrm{x}} .=e_{0}$. Fig. 1 shows that $\mu l_{x}+\mu r_{x}$ rises from 75.40 years when age $=$ zero reach a maximum of approximately 79.8 years at age 77 and remains approximately at this maximum until age 82 . It then declines back to 75.40 at the maximum possible age, which we set at 111 years. The 


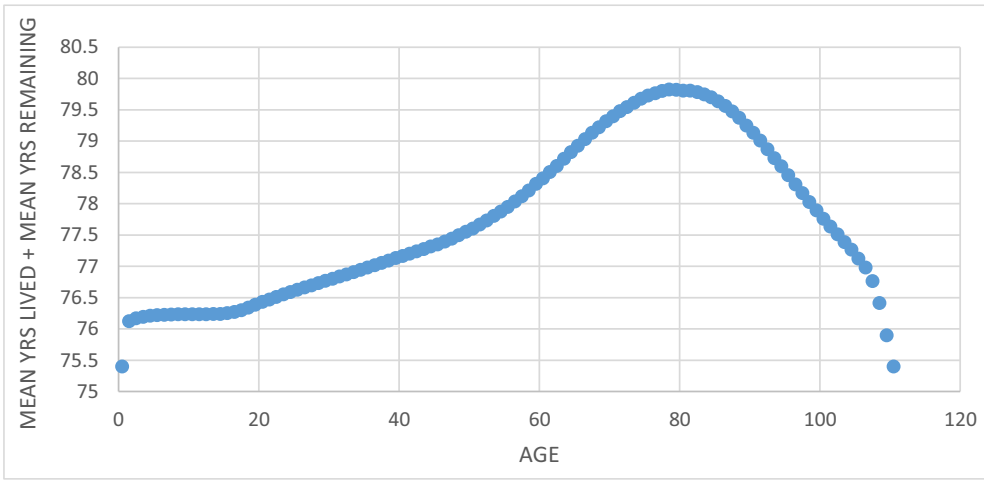

Fig. 1 Mean yrs lived + mean years remaining by age: 1990 US life table (stationary population)

plateau area between ages 77 and 82 is centered on 79.5 years, which is the sum of mean years lived, $\mu l$, and mean years remaining $\mu r$, for this life table (see Table 1 in the following section). As $\mu l_{x}+\mu r_{x}$ increases, the curve is steepest from age 45 to age 79 , and the decline from the end of the plateau is steep all the way to age 111.4

\subsection{Illustration of Theorem 2}

In order to empirically illustrate the inequality provided by theorem 2 and the relationship linking it to variance in age at death, we selected a (non-random) sample of complete US life tables for years ending in zero and five from the Human Mortality Database (2009), which has an online collection of these life tables annually from 1933 to 2013 . Table 1 provides 16 empirical examples of this inequality, namely, that $\mu \mathrm{l}+\mu \mathrm{r}>e_{0}$.

As it can be seen in Table 1, the difference between $\mu l+\mu r$, on the one hand, and, $e_{0}$, on the other, declines as $e_{0}$ increases from 1935 to 2010 . The mean difference over all 16 observations is 5.37 years, with a standard deviation of 1.90. Also seen in Table 1 is the inverse relationship between life expectancy at birth and variance in the age at death. As life expectancy at birth increases from 60.89 in 1935 to 78.85 in 2010, variance in the age at death decreases from 611.94 to 270.46 , respectively. This inverse relationship is consistent with the observation by Németh (2017) that as life expectancy increases, lifespan inequality decreases. Because of theorem 2 we know that the difference will remain positive from the re-expressed version of Eq. (3) found in the proof for theorem 2, namely, that $\mu 1+\mu \mathrm{r}=e_{0}+\left(\sigma^{2} / e_{0}\right)$.

In verbal terms, the explanation for the empirical illustration of the relationship specified in the non-linear equation given by $\mu \mathrm{l}+\mu \mathrm{r}=e_{0}+\left(\sigma^{2} / e_{0}\right)$ is that the sum of mean years lived $(\mu l)$ and mean years remaining $(\mu r)$ is equal to the mean age at death $(\mu \mathrm{d})$ plus the ratio of the variance in age at death to mean age at death $\left(\sigma^{2} / \mu_{d}\right)$. Recalling that mean age at death is equal to life expectancy at birth $\left(e_{0}\right)$, we can see that if the variance in age at death remained relatively constant (or, relatively speaking, did not increase as much as life expectancy) from 1935 to 2010 while life expectancy increased, then the difference, $\mu l+\mu r-e_{0}$, would decrease during the same period. To some extent, the trend implied by the data in Table 1 likely reflects this because other than the initial effect of the baby boom (1946-64), the US population aged between 1935 and 2010 and holding all else constant, variance in age at death does not increase as a population ages because deaths become more concentrated in 
Table 1 Difference between the sum of mean years lived and mean years remaining and life expectancy at birth: selected US life tables for both sexes combined, 1935 TO $2010(N=16)$

\begin{tabular}{lllllll}
\hline Year & $\begin{array}{l}\mathrm{e}_{0} \\
(1)\end{array}$ & $\begin{array}{l}\text { Variance } \\
\text { in age at death } \\
\sigma^{2} \\
(2)\end{array}$ & $\begin{array}{l}\text { Mean years } \\
\text { lived } \\
\mu_{\lambda} \\
(3)\end{array}$ & $\begin{array}{l}\text { Mean years } \\
\text { remaining } \\
\mu_{\mathrm{r}} \\
(4)\end{array}$ & $\begin{array}{l}\text { Total mean } \\
\text { years lived and } \\
\text { remaining } \\
\mu_{\lambda}+\mu_{\mathrm{r}} \\
(5)\end{array}$ & $\begin{array}{l}\text { Difference: } \\
(5)-(1) \\
(6)\end{array}$ \\
& & & 35.47 & 35.47 & 70.94 & 10.05 \\
1935 & 60.89 & 611.94 & 35.86 & 35.86 & 71.72 & 8.49 \\
1940 & 63.23 & 536.82 & 36.55 & 36.55 & 73.10 & 7.52 \\
1945 & 65.58 & 493.16 & 37.12 & 37.12 & 74.24 & 6.17 \\
1950 & 68.07 & 419.99 & 37.62 & 37.62 & 75.24 & 5.68 \\
1955 & 69.56 & 395.1 & 37.66 & 37.66 & 75.32 & 5.49 \\
1960 & 69.83 & 383.37 & 37.81 & 37.81 & 75.62 & 5.38 \\
1965 & 70.24 & 377.89 & 38.00 & 38.00 & 76.00 & 5.26 \\
1970 & 70.74 & 372.09 & 38.67 & 38.67 & 77.34 & 4.80 \\
1975 & 72.54 & 348.19 & 39.09 & 39.09 & 78.18 & 4.44 \\
1980 & 73.74 & 327.41 & 39.39 & 39.39 & 78.78 & 4.11 \\
1985 & 74.67 & 306.89 & 39.75 & 39.75 & 79.50 & 4.10 \\
1990 & 75.40 & 309.14 & 39.90 & 39.90 & 79.80 & 3.91 \\
1995 & 75.89 & 296.73 & 40.20 & 40.20 & 80.40 & 3.54 \\
2000 & 76.86 & 272.08 & 40.60 & 40.60 & 81.20 & 3.57 \\
2005 & 77.63 & 277.14 & 41.14 & 41.14 & 82.28 & 3.43 \\
2010 & 78.85 & 270.46 & & & & \\
\hline & & & & & & \\
\end{tabular}

Source: Human Mortality Data Base, as discussed in the text. Calculations are by the authors.

the older population, which, in turn, is reflected in life tables constructed from such a population (Engelman et al., 2010).

\section{Discussion}

Wrycza (2014) demonstrated that variance in age at death, $\sigma^{2}$, is equal to the average squared remaining life expectancy at death. Given this and the fact that Eq. (3) can be re-expressed as $\sigma^{2}=\left[e_{0}(\mu \mathrm{l}+\mu \mathrm{r})\right]-e_{0}^{2}$ (see endnote 2), we can see that average squared number of life-years lost due to death, $e_{d}^{2}$, is equal to subtracting life expectancy at birth squared, $e_{0}^{2}$, from the product, $e_{0}\left(\mu 1+\mu \mathrm{r}_{\mathrm{x}}\right)$. That is, $e_{d}^{2}=\left[e_{0}(\mu 1+\right.$ $\mu \mathrm{r})]-e_{0}{ }^{2}$. Wrycza's (2014) finding is equivalent to stating that when average squared number of life-years lost is divided by life expectancy at birth, it is equal to the difference between the sum of mean years lived and mean years remaining, on the one hand, and on the other, life expectancy at birth: $e_{d}^{2} / e_{0}=(\mu l+\mu r)-e_{0}$. This leads to viewing the sum of mean years lived and mean years remaining as being equal to life expectancy at birth plus the ratio of the average squared number of life years lost due to death to life expectancy at birth: $(\mu l+\mu r)=e_{0}+e_{d}^{2} / e_{0}$. Both of these equalities imply that if everybody lived to maximum life expectancy $\left(e_{0}=\omega\right)$, then $e_{d}^{2}=\sigma^{2}=0$ and $(\mu l+\mu r)=e_{0}$. 
Using Carey's Equality Theorem (Carey et al., 2008; Müller et al., 2004; Rao \& Carey, 2014) and a 2005 life table for the USA, Vaupel (2009) estimates that more than $48 \%$ are 41 years or older, which implies that nearly half of the life table population will be alive in 2050, assuming that the 2005 life table holds to 2009. Using the same US life table and corresponding stationary population, we find that on average the population lived 40.60 years and will live another 40.60 years on average. If we assume that the 2005 life table applied to 2009 as did Vaupel, then on average the members will live to almost 2050, which is in agreement with Vaupel's estimate. Even without such an assumption, it is the case that, on average, the 2005 population lived 40.6 years and will, on average, live another 40.6 years, or 81.3 years in total, which is 3.67 years more than their life expectancy at birth of 77.63 years. While the actual differences may vary, the proof shown earlier for theorem 2 shows that mean years lived + mean years remaining is greater than life expectancy at birth $\left(\mu l+\mu \mathrm{r}>e_{0}\right)$. If we apply this line of reasoning to the actual 2010 US life table, we find that, on average, the 2010 population lived 41.14 years and will, on average, live another 41.14 years, or 82.28 years in total, which is 3.43 years longer than this population's life expectancy at birth of 78.85 (see Table 1).

Vaupel (2009) notes that in regard to work by Müller et al. (2004) and Müller et al. (2007) on wildlife population dynamics, Carey's Equality Theorem could be used to estimate population age structure. In regard to this application, we add that if a representative age structure is obtained for a stationary population (or one that can be made stationary with adjustments suggested by Müller et al. (2004) and Müller et al. (2007), through Vaupel's suggestion or from another method, such as a sample, then its mean age, mean years lived, and mean years remaining can be determined as can its life expectancy at birth, its crude birth rate, and its crude death rate. If a representative age structure is obtained from a random sample, then interval estimates of these parameters can be constructed for the stationary population in question.

In the form of $\mu l_{x}$ and $\mu r_{x}$, Carey's Equality Theorem also manifests itself in the data displayed as Fig. 2, although somewhat imperfectly because the data we use to illustrate it are discrete rather than continuous. ${ }^{4}$ As can be seen in Fig. 2 , the plotted values of $\mu l_{x}$ are a mirror image of the plotted values of $\mu r_{x}$, slightly distorted at the tails by the fact the data are discrete. The point in Fig. 2 at which the two curves cross over one another is 39.75 years, which is the mean age of this stationary population (the point on the $\mathrm{x}$ axis at which the crossover occurs) and also both its mean number of years lived (the point on the y axis at which the crossover occurs) and mean number of years remaining (the point on the y axis at which the crossover occurs). That is, 39.75= $\mu \mathrm{a}=\mu l=\mu r$.

\section{Concluding Comments}

The inequality expressed as theorem 2 is counter-intuitive in that one does not expect the sum of mean years lived and mean years remaining to exceed life expectancy at birth (or equivalently, mean age at death) in the stationary populations underlying life tables constructed for human and other species. The underlying explanation of this inequality is linked to variance in age at death. For example, if variance in age at death is held constant and life expectancy (mean age at death) increases, then the inequality described by theorem 2 decreases; if variance in age at death increases and life expectancy is held constant, then the inequality described by theorem 2 increases. This 


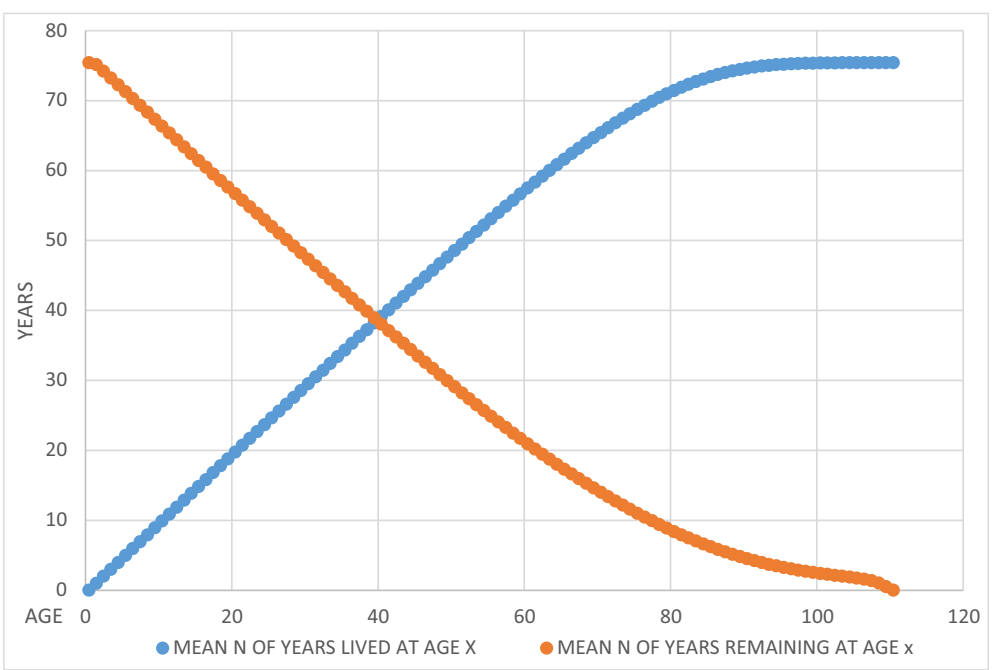

Fig. 2 Mean years lived $\left(\mu \mathrm{l}_{\mathrm{x}}\right)$ and mean years remaining $\left(\mu r_{x}\right)$ by age, 1990 US life table (stationary population)

explanation can be extended to theorem 1 by looking at the variance in age at death up to and including a given age. For example, if we are interested in the inequality found at age $\mathrm{x}$, we will find that if variance in age at death up to and including age $\mathrm{x}$ is held constant and life expectancy (mean age at death) increases, then the inequality described by theorem 1 decreases; if variance in age of death up to and including age $x$ increases and life expectancy is held constant then the inequality described by theorem 1 increases.

The only biological exception to theorems 1 and 2 would be a species with no variation in age at death. However, finding such a species is so unlikely that it would appear to be impossible. For species that are characterized by variation in age at death, one implication of these two related theorems is that the mean longevity of all of the "living" members of a given stationary population exceeds the mean number of years expected at birth. From a different perspective, Pressat (1972: 480) recognizes this inequality by stating that "the mean age of a stationary population is greater than half of the expectation of life." He follows this with an important observation, namely, that this inequality is due to variation in individual lengths of life. This variation is why the sum of mean years lived and mean years remaining exceeds life expectancy at birth (except at age zero and at the age representing maximum longevity where the sum is equal to life expectancy at birth, per the proof of theorem 1). This inequality suggests that when a life table is used for planning the future, it is worthwhile to keep in mind that life expectancy at birth understates average longevity for the "living" members of the life table population relative to the non-linear relationship found in the ratio of variance in age at death to life expectancy at birth. ${ }^{5}$ As such, when this ratio is elevated, then it may be preferable to use the sum of mean years lived and mean years remaining instead of life expectancy at birth in some applications. For a similar reason, this also suggests that at a given age, it may be preferable to use the sum of mean years lived to that age and mean years remaining at that age instead of simply using life expectancy at the age in question. ${ }^{6}$ 


\section{Endnotes}

1. As noted by Ryder (1975: 8-9), the ratio, $\sigma^{2} / e_{0}$, is equivalent to the coefficient of variation, as is $\sigma 2 / \mu_{\mathrm{d}}$. As such, when making comparisons across stationary populations in regard to variation in $e_{0}$ or $\mu_{d}$, it is more appropriate to use a coefficient of variation instead of $\sigma^{2}$. Following the observations of Pressat (1972: 480 ), it is worthwhile to note here that, when any subject is examined from the perspective of "longevity," the inequalities we have identified here will also be found where there is variation in individual longevity. Among many others, these subjects include, for example, duration of first marriage (Schoen, 1975), length of working life (Yusuf, Martins, and Swanson, 2014: 222-224), length of the second birth interval (Swanson, 1985, 1986), length of product reliability (Ebeling, 2010), length of time to product substitution (Martins et al., 2012: 169-189), duration of disability (Office of the Chief Actuary, 2002), and the longevity of species other than humans (Carey \& Judge, 2000).

2. It is worthwhile to note that re-arranging Eq. (3) provides a method for calculating the variance in $\mathrm{e}_{0}$ (and its equivalent, the variance in mean age at death):

$$
\sigma^{2}=\left[e_{0}(\mu l+\mu r)\right]-e_{0}^{2}
$$

This approach to calculating $\sigma^{2}$ is straightforward (for other ways to calculate $\sigma^{2}$ see, e.g., Hakkert, 1987; Hill, 1993; and Wrycza, 2014) because one can simply multiply mean age ( $\mu$ a) by 2 and substitute this in the right hand side of the equation in place of $\mu l+\mu \mathrm{r}$. This approach also provides a meaningful estimate of $\sigma^{2}$ that among other desirable characteristics includes mortality at all ages (see Wrycza, 2014 for a discussion of this issue), which has a range of applications (see, e.g., Schindler et al., 2012).

3. An anonymous reviewer pointed out that proofs of these inequalities could be constructed more efficiently from the perspective of continuous age and, in addition, two implications of this proof. In regard to the continuous age perspective, we followed this advice in the main body of the text, but also show the discrete approach in the appendix, which may be more familiar to many demographers. In regard to the two implications: the first is that if the distribution of age at death is exponential, then the mean and the variance are the same, which implies that the mean age at death and the mean age of the stationary population are equal; and the second is that the case where $\sigma^{2}=0$ has no practical interpretation, which means that the death distribution is degenerate.

4. Arni Rao suggested to us that theorem 1 has several implications, one of which is that, when $0<x<\omega$, the sum of mean years lived at age $x\left(\mu l_{x}\right)$ and mean years remaining at age $\mathrm{x}\left(\mu \mathrm{r}_{, \mathrm{x}}\right)$ is greater than mean years remaining at age $\mathrm{x}-1\left(\mu \mathrm{r}_{\mathrm{x}-1}\right)$.

5. Villavicencio and Riffe (2016) provide a complete and formal proof of Carey's equality in a discrete-time framework.

6. In addition to Pressat (1972), Morales (1989), Ryder (1975), and Preston (1991), among others, Canudas-Romo \& Zarulli, 2016), and Canudas-Romo and Engelman (2016) have examined mean years lived and mean years remaining. However, none of these authors describes the inequalities demonstrated here in the forms of theorems 1 and 2 . 


\section{Appendix. Proofs of theorems 1 and 2 from a discrete age perspective}

\section{Theorem 1}

When $0<\mathrm{x}<\omega$, then $\mu \mathrm{l}_{\mathrm{x}}+\mu \mathrm{r}_{\mathrm{x}}>\mu$.

\section{Proof}

Let the size of a stationary population be $T_{o}=k e_{0}$ where:

$k=$ radix of the life table (e.g., $k=100,000)=l_{0}$,

$e_{0}=$ life expectancy at birth $=$ mean years lived, $\mu=$ mean age at death, $u d$. Then:

$\mu \mathrm{l}_{x}=\left(T_{0}-T_{x}\right) / l_{0}=$ mean years lived to age $\mathrm{x}$ and

$\mu \mathrm{r}_{x}=T_{x} / l_{x}=$ mean years remaining at age $\mathrm{x}$.

Because $\mu l_{x}=\left(T_{0}-T_{x}\right) / l_{0}=\left(\mu l_{0}-T_{x}\right) / l_{0}=\mu-T_{x} / l_{0}$

then $\mu \mathrm{l}_{x}+\mu \mathrm{r}_{x}=\mu-T_{x} / l_{0}+T_{x} / l_{x}$

and except when $\mathrm{x}=0$, so that $T_{x} / l_{0}=T_{0} / l_{0}=\mu$

and when $T_{x} / l_{x}=T_{0} / l_{0}$ so that $\mu-T_{0} / l_{0}+T_{0} / l_{0}=0+\mu=\mu$

and except when $\mathrm{x}=\omega$, so that $T_{x} / l_{0}=T_{\omega} / l_{0}$

and when $T_{x} / l_{x}=T_{\omega} / l_{\omega}$, so that $\mu-T_{\omega} / l_{0}+T_{\omega} / l_{\omega}=\mu-0 / l_{0}+0 / 0=\mu-0+0=\mu$ then $T_{x} / l_{0}<T_{x} / l_{x}$ because $l_{0}>l_{x}$ when $\mathrm{x}>0$.

Thus, $\mu \mathrm{l}_{x}+\mu \mathrm{r}_{x}>\mu$ because $\mu-T_{x} / l_{0}+T_{x} / l_{x}>\mu$. This completes the proof.

\section{Theorem 2}

$$
\mu l+\mu r>\mu
$$

\section{Proof}

Equation (2), the equality identified by Pressat (1972) described in the text, is useful here because it provides a straightforward basis for proving the inequality given in theorem 2. First, recall that, as shown in the text, the mean age of the stationary population is equal to mean years lived and to mean years remaining: $\mu \mathrm{a}=\mu l=\mu r$ and, therefore $=2 \mu a=2 \mu l=2 \mu r$. Thus, if we multiply $\mu a$ by 2 , then eq. (2) can be restated as

$$
e_{0}+\left(\sigma^{2} / e_{0}\right)=2 \mu a=2\left(0.5\left(e_{0}+\left(\sigma^{2} / e_{0}\right)\right)\right)
$$

Because $2 \mu a=(\mu l+\mu r)=e_{0}+\left(\sigma^{2} / e_{0}\right)$, the sum of mean years lived and mean years remaining is equal to the sum of life expectancy at birth and the ratio of variance in age at death to life expectancy at birth. Further, where $\sigma^{2}>0$, then it follows that $\mu l+$ $\mu r>e_{0}$ and where $\sigma^{2}=0$, then $\mu l+\mu_{r}=\mu=e_{0}$. This completes the proof. 
Acknowledgements We are grateful to two anonymous reviewers for their comments on the submitted paper and to Jakub Bijak, Arni Rao, Robert Schoen, and Anatoliy Yashin for comments on earlier versions of this paper, which was presented at the 2016 annual conference of the British Society for Population Studies, University of Winchester. An earlier version of this paper appears in two non-refereed online venues: (1) the Casualty Actuarial Society's E-Forum (http://www.casact.org/pubs/forum/16fforum/03-SwansonTedrow.pdf) and (2) The Actuarial Research Clearing House of the Society of Actuaries (https://www.soa.org/Library/ Proceedings/Arch/2017/arch-2017-iss1.aspx).

Open Access This article is licensed under a Creative Commons Attribution 4.0 International License, which permits use, sharing, adaptation, distribution and reproduction in any medium or format, as long as you give appropriate credit to the original author(s) and the source, provide a link to the Creative Commons licence, and indicate if changes were made. The images or other third party material in this article are included in the article's Creative Commons licence, unless indicated otherwise in a credit line to the material. If material is not included in the article's Creative Commons licence and your intended use is not permitted by statutory regulation or exceeds the permitted use, you will need to obtain permission directly from the copyright holder. To view a copy of this licence, visit http://creativecommons.org/licenses/by/4.0/.

\section{References}

Burch, T. (2018). Model-based demography: Essays on integrating data, technique, and theory. Springer.

Canudas-Romo, V. (2010). Three measures of longevity: Time trends and record values. Demography, 47(2), 299-312.

Canudas-Romo, V., \& Engelman, M. (2016). Maximum life expectancies: Revisiting the best practice trends. Genus, 65(1), 59-79.

Canudas-Romo, V., \& Zarulli, V. (2016). Am I halfway? Years lived = expected life. In R. Schoen (Ed.), Dynamic demographic analysis (pp. 33-50). Springer. Dordrecht.

Carey, J. R., \& Judge, D. (2000). Longevity records: Life spans of mammals, birds, reptiles Amphibians and Fishes. Odense University Press.

Carey, J. R., Papadopoulos, R., Müller, H.-G., Katsoyannos, B., Kouloussis, B. N., Wang, J.-L., Wachter, K., Yu, W., \& Liedo, P. (2008). Age structure and extraordinary life span in wild medfly populations. Aging Cell, 7, 426-437.

Ebeling, C. (2010). An introduction to reliability and maintainability engineering (2nd ed.). Waveland Press. Long Grove Il.

Engelman, M., Canudas-Romo, V., \& Agree, E. (2010). The implications of increased survivorship for mortality variation in aging populations. Population and Development Review, 36(3), 511-539.

Frauenthal, E. (1986). Analysis of age structure models. In T. Hallam \& S. Levin (Eds.), Biomathematics 17. Mathematical Ecology: An Introduction (pp. 117-147). Springer-Verlag.

Hakkert, R. (1987). Life table transformations and inequality measures: Some noteworthy formal relations. Demography, 23, 615-622.

Hill, G. (1993). The entropy of the survival curve: An alternative measure. Canadian Studies in Population, 20, 43-57.

Human Mortality Database. (2009) University of California, Berkeley, and Max Planck Institute for Demographic Research. www.mortality.org.

Kim, Y., \& Aron, J. (1989). On the equality of average age and average expectation of remaining life in a stationary population. SIAM Review, 31(1), 110-113.

Kintner, H. (2004). The life table. In J. Siegel \& D. Swanson (Eds.), The Methods and Materials of Demography (2nd ed., pp. 301-340). Elsevier Academic Press.

Kintner, H., \& Swanson, D. (1994). Estimating vital rates from corporate databases: How long will general Motors' salaried retirees live? In H. Kintner, T. Merrick, P. Morrison, \& P. Voss (Eds.), Demographics: A casebook for business and government (pp. 265-297). Westview press: Boulder.

Martins, J., Yusuf, F., \& Swanson, D. (2012). Consumer demographics and behaviour. Springer.

Morales, V. (1989). Mean age and life expectancy at birth in stationary populations: Research note. Social Biology, 36(1-2), 114. 
Müller, H.-G., Wang, J.-l., Carey, J., Caswell-Chen, E., Chen, C., Papadoupoulos, N., \& Yao, F. (2004). Demographic window to aging in the wild: Constructing life tables and estimating survival functions from marked individuals of unknown age. Aging Cell, 3(3), 125-131.

Müller, H.-G., Wang, J.-L., Yu, W., Delaigle, A., \& Carey, J. (2007). Survival in the wild via residual demography. Theoretical Population Biology, 72(4), 513-522.

Németh, L. (2017). Life expectancy versus lifespan inequality: A smudge or a clear relationship? PLoS One, 12(9), e0185702.

Office of National Statistics. (2017). Most common age at death, by socioeconomic position in England and Wales: a 30 years comparison. (https://www.ons.gov.uk/peoplepopulationandcommunity/ $\mathrm{h}$ e a $1 \mathrm{th}$ a nd s o c i a $1 \mathrm{c}$ a $\mathrm{re} / \mathrm{h}$ e a $1 \mathrm{th} \mathrm{h}$ e qua $1 \mathrm{ities} / \mathrm{articles} /$ mostcommonageatdeathbysocioeconomicpositionsinenglandandwales/a30yearscomparison).

Office of the Chief Actuary. (2002). Canada pension plan experience study of disability beneficiaries. In Actuarial Study no. 1. Office of the Superintendent of financial institutions. Government of Canada http:// www.osfi-bsif.gc.ca/eng/docs/cpp_disability_paper.pdf.

Pearson, K. (1924). Note: To prove that the expectation of life at any age is greater than the mean age of all persons living greater than this age. Biometrika, 16(3/4), 297-298.

Pressat, R. (1972). Demographic analysis: Methods, results, applications. Aldine-Atherton.

Preston, S. (1991). Mean age and life expectancy at birth in stationary populations: Comment. Social Biology, $38(1-2), 154$.

Rao, A., \& Carey, J. (2014). Generalization of Carey's equality and a Theorem on stationary population. Journal of Mathematical Biology, 71, 583-594. https://doi.org/10.1007/s00285-014-0831-6. http:// entomology.ucdavis.edu/files/203430.pdf.

Richards, H., \& Donaldson, M. (2010). Life and worklife expectancies. Lawyers and Judges Publishing.

Ryder, N. (1975). Notes on stationary populations. Population Index, 41(1), 3-28.

Schindler, S., Tuljapurkar, S., Gaillard, J., \& Coulson, T. (2012). Linking the population growth rate and the age-at-death distribution. Theoretical Population Biology, 82(4), 244-252.

Schoen, R. (1975). California divorce rates by age at first marriage and duration of first marriage. Journal of Marriage and Family, 37(3), 548-555.

Shkolnikov, V., Andreev, E., \& Begun, A. (2003). Gini coefficient as a life table function: Computation from discrete data, decomposition of differences and empirical examples. Demographic Research, 8(11), 305358.

Siegel, J. (2002). Applied demography. Academic Press.

Smith, S., Tayman, J., \& Swanson, D. (2013). A practitioner's guide to state and local population projections. Springer.

Swanson, D. (1985). The timing of fertility: Mathematical models and socio-demographic aspects of the second birth interval. Unpublished Ph.D. dissertation, University of Hawai'i. Honolulu, HI.

Swanson, D. (1986). Timing the second birth: Fecundability models for selected race and age groups in Hawai'i. Janasamkhya, 4(December), 82-113.

Swanson, D., \& Sanford, A. (2012). Socio-economic status and life expectancy in the United States, 19902010: Are we reaching the limits of human longevity? Population Review, 51(2), 16-41.

Swanson, D., \& Tedrow, L. (2012). Using cohort change ratios to estimate life expectancy in populations with negligible migration: A new approach. Canadian Studies in Population, 39, 83-90.

Thomas, J., \& Bao, L. (2016). Modeling the dynamics of an HIV epidemic. In R. Schoen (Ed.), Dynamic demographic analysis (pp. 91-114). Springer. Dordrecht.

Trovato, F., \& Lalu, N. M. (2001). Narrowing sex differences in life expectancy: Regional variations, 19711991. Canadian Studies in Population, 28(1), 89-110.

Vaupel, J. (2009). Life lived and left: Carey’s equality. (2009). Demographic Research, 20, 7-10.

Villavicencio, F., \& Riffe, T. (2016). Symmetries between life lived and left in finite stationary populations. Demographic Research, 35, 381-398.

Wrycza, T. (2014). Variance in age at death equals average squared remaining life expectancy at death. Demographic Research, 30(50), 1405-1412.

Yashin, A., Stallard, E., \& Land, K. (2016). Biodemography of aging: Determinants of healthy life span and longevity. Springer.

Yusuf, F., Martins, J., \& Swanson, D. (2014). Methods of demographic analysis. Springer. 


\section{Affiliations}

\section{David A. Swanson ${ }^{1} \cdot$ Lucky M. Tedrow $^{2}$}

1 Center for Studies in Demography and Ecology, University of Washington, Seattle, Washington 98195, USA

2 Department of Sociology, Western Washington University, Bellingham, Washington 98225, USA 